young people, seems to me quite clear; but it is curious, in other cases, how difficult it is to find ill effects, even in the young, when the quantity is not excessive.

As to the effect on the young even, it is curious in Burmah to see children smoking in their mothers' arms; and yet when I was serving in Burmah, many years ago, I often saw a woman walking along smoking her cigar of tobacco rolled up in a plantain-leaf, and carrying on her hip her child of two or three years old, who also had his or her little cigar, which was smoked with the greatest gravity. On talking to the Burmese (who smoke constantly), they would never allow that even young children were in the least damaged. When I was in Turkey I tried to make inquiries of some of the intelligent Turkish gentlemen; one or two of them said that they thought the Turks had learnt to smoke from the Europeans, and had been growing apathetic and dull ever since. But others laughed at this, and the rural Turk, who smokes a good deal, is a fine, active, energetic fellow.

I have talked to many Germans, who all stand out manfully for tobacco.

In conclusion, I confess myself quite uncertain. I can find nothing like good evidence in books ; too often a foregone conclusion, without any evidence to back it, is given.

I think we must decidedly admit injury from excess; from moderate use I can see no harm, except it may be in youth.

My opinions are, you will see, very indefinite, and I would gladly see some really good evidence collected. If at any time you can send me any facts, I shall be very grateful.

Believe me, very sincerely yours,

Bitterne, Southampton, Jan. 28, 1876.

E. A. PARKes.

\section{ON EXTRACTION OF CATARACT BY SUCTION.}

To the Editor of THE LANCET.

SiR,-In The LANCET of Dec. 6th, p. 828, Dr. Wolfe says of suction in the extraction of soft cataract:- "Having been an opponent of the introduction of pumping instruments into the cornea for soft cataract operations, when first recommended, I am gratified to see that several surgeons of eminence, who, led by high authority, then advocated that system, have, after experiencing disasters, come to my way of thinking."

Such a condemnation by one of the leading ophthalmic surgeons of Scotland is likely to discredit the operation of suction.

As the introducer of this method into British ophthalmic surgery, I feel called upon to vindicate its claims to the confidence of the profession; and having used the method for nearly twenty years in perhaps three-fourths of my cases of soft cataract, I may fairly lay claim to an opinion of some weight against that of one who was "an opponent of the operation when first recommended," and " is gratified that several surgeons of eminence," having had disasters, "have come to " his " way of thinking."

The fact is that, like many good things, it is liable to be misused, and perhaps I am myself not altogether free from blame in not having written more fully upon its difficulties and dangers, especially when it came to my knowledge that disasters had occurred in the hands of some ophthalmic surgeons.

As a fair and impartial judgment upon the operation, I cannot do better than quote the opinion of Mr. R. B. Carter, in his work " on Diseases of the Eye," 1875 , p. 362 :- "If I had been writing a little more than a year ago, I should have describec the method as being practically free from danger; for at that time I had never seen it followed by any result except a good recovery. But, . . . my recent experience would lead me to speak of suction with somewhat diminished confidence, but I still think it the best method of removing cataracts in the cases for which it is suited. It is not, as I once believed, almost without risk, but I still think that the risks it entails are less than those which attend upon other methods; and $I$ am not at all satisfied that the unfavourable results in the cases above-mentioned may not have been due to causes not essentially connected with the procedure. It is difficult to clean the suction curette thoroughly, and it cannot be put into hot water without dissolving the cement which unites the silver portion of its tube to the glass. It occurred to me that the ordinary washing with cold water after use might have left some particles of organic matter in the channel, and that these accidentally introduced into other eyes at subsequent periods might have excited the inflammation described. I have since taken the precaution of soaking the curette for some hours in dilnted Condy's fluid, and of then washing it well in pure water immediately before an operation, and my cases subsequent to the adoption of this precaution have done well. Mr. Teale informs me that his own experience of suction is highly favourable. but I have heard less satisfactory reports from other sources." Let me now summarise my ideas and matured views in the following propositions:-

1. When a cataract is almost fluid it will readily flow out in the groove of the ordinary curette, and there is no need of extraction by suction.

2. When a cataract is immature or semi-solid, to attempt to withdraw it by suction is to put enormous atmospheric pressure upon the ocular structures and to risk disaster.

3 . For cataracts between these extremes-and they constitute a large proportion of soft cataracts-there is no method, to my mind, more simple, more speedy, more effectual, more safe, or less liable to be followed by opacity of the capsule, than the method of suction.

4. To use a suction instrument with safety requires atten tion to minute details, no less than is needed for the use of the lithotrite. Lithotrity carelessly performed becomes disastrous. Performed with due care and gentleness, it is one of the most successful of the major operations of surgery.

5. The safest form of suction instrument is the one in which the action is regulated by the mouth. The "pump syringes" are more difficult to use, and do not admit of an equal delicacy in the regulation of the suction power, and, therefore, demand most exquisite manipulation in the operator.

6. The aperture in the curette ought to be oval, and level with the upper surface of the curette, so that on the completion of the flow of cataract the cornea may close the opening and act as a valve, arresting further and mischievous suction. It is this valve-like action of the cornea which is one great safeguard in the use of suction, a safeguard which is impossible in the case of the instruments made some years ago, in which the opening was enlarged by notches at the side.

7. The suction force ought to be applied with gentleness, with short draws of the mouth, and with no great force. If the cataract proves to be stiff, and requires great suction power, the attempt to extract by suction should be abandoned, and further proceedings should be deferred until the wound is soundly healed.

8. On no account whatever ought transparent lens to be withdrawn by suction. Firstly, because it is too firm to be safely drawn into the curette; secondly, because, owing to its transparency, it is impossible to judge whether the whole lens has been removed or not.

9. "When the lens is of firmer consistence, and the aspirator drags upon the vitreous and other delicate structures, and is sure to do mischief" (Dr. Wolfe), to use suction is surely to misuse it. It is hardly fair to condemn the use of a method bocause abuse of it produces disaster.

10. It is of supreme importance to preserve the posterior capsule of the lens unruptured, otherwise the vitreous humour comes forward, and is drawn into the curette instead of the lens.

In conclusion, may I venture to refer to my own experi. ence in support of the views herein expressed?

As far as I can recollect, I have had but three cases of destructive inflammation after the use of suction. In the first case, a syphilitic boy, diffuse keratitis set in, first in the eye operated upon; afterwards in the untonched eye. The other two cases occurred about six years ago, so closely upon each other that I suspect that some such cause as suggested by Mr. Carter may be the explanation-viz., that the curette conveyed decomposing material into the eye.

On referring to the notes of my private operations for soft cataract (the record of my hospital cases not being complete enough for comparison), I find that of my last fifty-three cases of soft cataract, in forty-seven suction has been used. Or these only one has been lost by destructive inflammation. Of the forty-seven, seventeen are noted as reading No. 1 or 2 Jäger. Of the remaining thirty, many are noted as "good sight "; many were too young to have therr sight tested; and 
two or three, though perfect as operations, had defective retinæ. These facts, though very imperfect as statistics, show-1. That I am still as convinced of the value of suction in the treatment of soft cataract as when I first brought it out. 2. That it is possible to use suction extensively without " experiencing disasters."

I am, Sir, yours faithfully,

Leeds, December 13th, 1879. T. PRidgix Teale.

\section{TYPHOID FEVER.}

To the Ecitor of THE LANCET.

SIR, - I beg to enclose an interesting communication, recently received, on the subject of typhoid fever. It seems to confirm, so far, the view advocated by me at the Epidemiological Society, that a fever, having all the symptoms and pathological conditions peculiar to enteric fever of this country, does exist in tropical and subtropical climates, but that it is not always due to the specific causes that are believed to give rise to it here.

If such be the case, and I have long been of opinion that it is so, is it not possible that the typhoid of Europe generally, and even sometimes of our own island, may have origin in other causes than the filth to which, in most cases, it is rightly assigned? I hope other medical men practising abroad will communicate their views or experience on this interesting subject.

Dec. $24 \mathrm{th}, \mathrm{I} 879$. I am, Sir, yours, \&c.,

To Sir J. FAYreR, M.D., \&e.

Sir,-I have to-day read, with great interest, in THE LANCET, your letter of the 9 th instant, with accompanying letter from Dr. Grabham, of Madeira, corroborating opinions lately published by you on the etiology of typhoid "feverwhich, unfortunately, I have not seen, as I have only just returned from the seat of war in Zululand, -in which you say, "Possibly other medical officers practising abroad in tropical or subtropical climates may be able to confirm the opinion, that fevers of climatic origin do occasionally present all the symptoms that characterise typhoid in this country."

Three days ago I sent a short paper on this subject to the British Mectical Journal, written last year, before leaving for South Africa, giving the result of sixteen years' experience in this matter in New Zealand, Fiji, Western and South Australia, and New South Wales, after adding that my latest experience of the fever, as it occurred among the troops in Zululand, coincided with my previous experience as above, which is as follows:- -1 . That a fever occurs frequently in all those countries, having all the characteristic symptoms of typhoid fever as it occurs in this country. 2 . That in no case, althongh every pains was taken by me, especially when I held the office of Provincial Surgeon of Westland, have I been able to trace the origin of the fever to contagion. 3. That in a few cases that disease seemed to have arisen from the fouling of the drinking water by excremental matter in a state of putrefaction. In the majority of cases the fever has broken out among Europeans first inhabiting or cultivating a virgin soil, the "new comers" being most liable to attack, apparently, as in Westland, from decaying vegetable matter, paludal emanations, or other climatic causes.

The importance of this matter, not merely from a scientific view, but to the practical physician and sanitarian, must be my excuse for thus addressing you. I may say apropos of this, and in conclusion, that some of the army surgeons and others in South Africa call the fever in question a "hybrid fever," between typhoid and remittent, and treat it, as remittent fever, with large doses of quinine. When I inquired the meaning of the term, or the reason for its application, I found it was not because the fever presented any remission or differed essentially from typhoid fever as it occurs in this country, but because of the difficulty of accounting under the circumstances for true typhoid by those who hold the views of Dr. Budd or Sir Thomas Watson, or even those of the lamented Dr. Murchison, as to its genesis or etiology.

I am, Sir, yours obediently,

J. RutheRford RYLEY, F.R.C.S. Edin,, L.R.C.P. Edin.

Edinburgh, December 13th, 1879.
TREATMENT OF TRANSVERSE FRACTURE OF THE PATELLA.

To the Editor of THE LANCET.

Sin,-As the treatment of transverse fracture of the patella is now much discussed, I beg you to insert the following notes in your much valued journal.

I have read with much interest in THE LANCET an abstract of the paper read by Mr. Royes Bell in the Medical Society of London, and the discussion that took place thereafter, as I practised the metallic suture in a case of transverse fracture of the patella as long ago as July, 1878, and published this case in the Nederlandsch tydschrift voor Genustande (Dutch periodical of medicine). As Mr. Royes Bell indicated that Mr. Rose (I believe, surgeon to the same hospital as Mr. Royes Bell) would read a more complete paper on this subject, I have sent to Mr. Royes Bell the above-named publication.

Since Mr. Rose, in his paper read 17 th November in the Medical Society, has not mentioned my case, perhaps because neither Mr. Bell nor Mr. Rose understands the Dutch language, I beg you (notwithstanding your unsympathetic judgment of this line of treatment in your "Annotations" in the number of Nov. 29, and the letter of Mr. A. Pearce Gould in the same number) to insert the following very brief notes of my case.

A married woman, aged forty-four, entered the Chirurgical Clinique of the University of Utrecht on July 6th, 1878. On examination I found a complete transverse fracture of the right patella, that occurred the day before. The knee-joint was not much swollen, but a soft, and a little prominent, blood coagulum was distinctly felt between the two halves of the broken patella. By means of the ordinary bandages it was impossible to hold the two fragments in complete juxtaposition. Therefore, and as I had never seen in hundreds of operations that fresh-cut wounds under the most accurate antiseptic precautions of Lister were followed by suppuration, or other accidental wound complications, I thought it right to cut down to the fractured patella, to remove the blood coagulam, and to unite accu. rately by means of metallic snture the two halves of the broken patella. This I made accordingly on the 13th July, eight days after the accident, by a longitudinal incision of the length of seven or eight centimetres over the mialle of the patella, and dissected the soft parts from the fibrous capsule on the front of the patella to both sides, so as to lay open to the sight the interstice between the bone fragments. Partly with the fingers, partly with a curette of Volckmann, I now removed the blood coagulum, washed the interstice between the fragments with $2 \frac{1}{2}$ per cent. carbolic solution, bored a little canal through the corresponding parts of the fragments of the patella, not perforating its posterior surface; introduced a soft platina wire, twisted the fragments together, and fixed the suture by torsion. The platina wire was cut short, and the cut end depressed in the fibrous tissue on the front part of the patella. The bone fragments were by this single suture brought so accurately together that more metallic sutures would have been superffuous; therefore $I$ united the fibrous tissue on the front of the patella by two catgut sutures on both sides of the platina suture, and closed the external wound by nine aseptic silk sutures, without inserting a drainage tube. A typical Lister bandage was applied with moderate firmmess around the knee-joint. Before the operation the knee was shaved, cleansed with ether and strong carbolic solution, and the operation performed under spray-in one word, with all Lister's antiseptic precautions.

On July 1Sth this first antiseptic bandage was removed. to take out the silk sutures, and anew one applied, so that the suture canals mightnot become the porte d'entrée of infection. This bandage was removed on the 2nd of August, and the wound found united as beautifully as in the most perfect plastic operation. A plaster-of-Paris bandage was now applied from the middle of the leg to the middle of the thigh and renewed on August 17th, when the patient was permitted to leave the bed and to walk round the ward. With this bandage the patient was dismissed on August 23rd. Three weeks thereafter the woman returned; the bandage was removed, and the joint found perfectly cured, 